\section{A Schoolboy's Survey of Vegetation of a Valley}

Blunderl's School, Tiverton, may well be proud of R. G. Pembrey, who was awarded the Senior Batterbee Prize in 1957 for an investigation into the factors underlying the differences in vegetation on the north-and south-facing slopes of a steep valley in spring. Pembrey compared the vegetation on the two slopes, analysed the soils at different levels and made observations on the bedding plane of the rocks, recorded environmental factors like soil, temperature and light intensity and made various records comparing the performance of different species on the two slopes. These included the rate of elongation of stems of bramble and yellow archangel, the internode length in ash seedlings, and the times of bursting of beech buds. The differences in the vegetation on the two slopes are due to a more rapid warming of the soil on the south-facing slopes, which allows the growth of a spring ground flora before the bursting of the beech buds. This is directly connected with the far higher light intensity on this slope. On the opposite slope, light intensity and soil temperatures are too low to support a spring flora. A full report of the investigation is described in the School's Science Magazine, which contains reports of other interesting work by schoolboys.

\section{Volcanic Eruptions in Kamchatka}

THe extinct or dormant volcano Bezymyannyi (also known as Sopka Bezymyannaya), belonging to the Klynchevsky group of volcanoes of Kamchatka, revived its activity on September 29,1955 , in the form of a series of volcanic earthquakes, followed on October 22, 1955, by eruptions terminating, on March 30,1956 , in a gigantic explosion which removed the greater part of the cone and formed a new cratercaldera. The progress of this activity was observed by G. S. Gorshkov and his companions and is described by him in two articles (Bull. Volcan. Station, No. 26, Acad. Sci. U.S.S.R., 1957; Priroda, 1, 61 ; 1958). The violent explosions of this volcano gave rise to large masses of volcanic ash which, mixing with melting snow, formed a series of mud flows, some $60 \mathrm{~km}$. in length with a calculated volume of 3 cubic kilometres. These flows became covered with a large number of secondary fumaroles in such a way that the whole district resembled the Valley of Ten Thousand Smokes of the Katmai eruption of 1912 in Alaska. According to Gorshkov, the calculated total energy of the volcanic explosive activity was $4 \times 10^{23} \mathrm{ergs}$, while the total thermal energy evolved was $3.6 \times 10^{25} \mathrm{ergs}$. This shows that the force of the eruption was due to the thermal energy of the magma and that the gas acted mainly as the transformer of the thermal energy into the explosion energy. During the final stages of the eruption a large plug-dome of andesitic lava was intruded in the crater-caldera of the volcano.

\section{Reduction of Evaporation from Reservoirs}

IN an article in the World Meteorological Bulletin of April 1958 and in a report on the use of cetyl alcohol in solution to reduce evaporation from reservoirs Mr. F. Grundy gives an account of an experiment conducted on Malya reservoir in Tanganyika Territory during August 1957 (Memoirs of the East African Meteorological Department, 2, No. 11 ; 1958. Nairobi : East African Meteorological Department, 1958. Sh. 4). The subject is one of particularly great importance in tropical areas where loss of water by evaporation can be several times the volume drawn for use. The work in East Africa began with tests in evaporation pans in the grounds of the Meteorological Office at Nairobi, which showed reduction of loss by about 60 per cent. Work on the Malya reservoir (130 acres) was more difficult because of disturbance by wind, and it was found better to use the alcohol dissolved in such solvents as kerosene rather than in solid form. The solution has to be applied continuously from sources on the upwind shore or preferably, because of better adjustment to wind changes, from a boat. The observations were made during the dry season to avoid complications due to rain. By computing the evaporation-loss from the inflow and outflow and comparing with evaporation from neighbouring evaporation pans it was estimated that the evaporation-loss was reduced by 11 per cent. The amount of cetyl alcohol used was $18 \mathrm{lb}$. day. It is not poisonous to man or animals, but its effects on fish are not yet known. Mr. Grundy considers that the experiments show an adequate film of cetyl alcohol can be maintained, but that further research is needed, especially on the method of applying the substance and avoiding wastage from its oxidation by organic matter. The cost is not likely to be excessive.

\section{Nomenclature of Cultivated Plants and of Fungi Pathogenic to Man}

I $T$ is now generally accepted that agreed international codes of nomenclature are essential to progress and unity of effort in the biological sciences; and cultivated plants, being essential to civilization, should be brought fully within "a precise, stable and internationally accepted system". So states Article 1 of "The International Code of Nomenclature for Cultivated Plants" (1958), now published by the International Bureau for Plant Taxonomy and Nomenclature of the International Association for Plant Taxonomy (106 Lange Nieuwstraat, Utrecht, and Royal Horticultural Society, London. $2 s .6 d$.) In this short but valuable publication, to which many distinguished botanists have contributed, all relevant issues are considered with clarity and precision. In the same general category, but dealing with very different subject-matter, the Medical Research Council has now published a revised edition of Memorandum No. 23, first issued in 1949 ("Nomenclature of Fungi Pathogenic to Man and AnimalsNames recommended for use in Great Britain". Second edition. Pp. iii +14 . London: H.M. Stationery Office, 1958. 1s. 3d. net). Here, again, it is noted how much progress in medical mycology has been hindered by the multiplicity of names for fungi associated with certain human and animal diseases. The nomenclatural issues here can be very complex indeed, and both knowledge and judgment are essential to sound decisions. In this small pamphlet an exacting task has been ably performed.

\section{Peruvian Orchids}

ThE Orchidaceae not only vie with the Compositae as a family comprising a vast number of species-somewhere between 15,000 and 35,000 according to contemporary estimates-but they are also undoubtedly among the most advanced group of the monocotyledons. A further contribution to our knowledge of this family comes from Peru, where 